\title{
Practical Considerations for Converting Operating Rooms and Post-anaesthesia Care Units into Intensive Care Units in the COVID-19 Pandemic - Experience from a Large Singapore Tertiary Hospital
}

Zihui Tan, ${ }^{1,2}{ }_{M B C h B}$, MMed, Priscilla Hui Yi Phoon, ${ }^{1,2}$ MBBS, MMed, FANZCA, Claudia Jong-Chie Tien, ${ }^{1}$ MBBS, MMed, FANZCA, Johari Katijo, ${ }^{1}$ Dip Electronic and Computer Engineering, Shin Yi Ng, ${ }^{1}$ MBBS, MMed, EDIC, Meng Huat Goh, ${ }^{1,2}$ MBBS, MMed, FANZA

\begin{abstract}
COVID-19 has spread globally, infecting and killing millions of people worldwide. The use of operating rooms (ORs) and the post-anaesthesia care unit (PACU) for intensive care is part of surge response planning. We aim to describe and discuss some of the practical considerations involved in a large tertiary hospital in Singapore. Firstly, considerations for setting up a level III intensive care unit (ICU) include that of space, staff, supplies and standards. Secondly, oxygen supply of the entire hospital is a major determinant of the number of ventilators it can support, including those on non-invasive forms of oxygen therapy. Thirdly, air flows due to positive pressure systems within the OR complex need to be addressed. In addition, due to the worldwide shortage of ICU ventilators, the US Food and Drug Administration has granted temporary approval for the use of anaesthesia gas machines for patients requiring mechanical ventilation. Lastly, planning of logistics and staff deployment needs to be carefully considered during a crisis. Although OR and PACU are not designed for long-term care of critically ill patients, they may be adapted for ICU use with careful planning in the current pandemic.
\end{abstract}

Keywords: Critical care, hospital management, surge response

Despite being one of the first countries to be affected by COVID-19, Singapore has responded quickly to control the disease. ${ }^{1}$ It has been able to implement measures to prevent its healthcare system from being overwhelmed, while conducting studies into the clinical features, management and outcomes of COVID-19 patients with respiratory failure admitted to intensive care units (ICUs). ${ }^{2}$ A recent review shows how the country has managed in containing COVID-19 based on available published data and from relevant sources. ${ }^{3}$

The COVID-19 pandemic represents the largest public health crisis since the severe acute respiratory syndrome (SARS) outbreak in 2003, especially for Singapore. ${ }^{4-6}$ The use of operating rooms (ORs) and the post-anaesthesia care units (PACUs) for intensive care is part of surge response planning. In this paper, we describe and discuss some of the practical considerations when using the ORs and PACUs as ICUs in a large tertiary hospital in Singapore.
Surge Response. The COVID-19 pandemic has exerted a burden unparalleled in modern history on both healthcare workers and resources. Between 5 and $16 \%$ of patients who test positive for COVID-19 will require critical care in an ICU. $^{7-9}$ During a pandemic, the expansion of intensive care services is divided into 3 response categories that exist as a continuum: conventional, contingency and crisis. ${ }^{10}$ A surge response occurs in Category 3 where ICU capacity hits over 200\% and standards of care are compromised.

The Singapore General Hospital ( $\mathrm{SGH}$ ) is a 1,700-bedder public hospital and is the largest academic tertiary-level acute care hospital in Singapore. During peacetime, the total ICU capacity within the campus is 58 beds. However, up to 120 critically ill patients could be potentially cared for by overflowing to highdependency units, OR and PACU with cancellation of elective surgeries.

\footnotetext{
${ }^{1}$ Division of Anaesthesiology, Singapore General Hospital, Singapore

${ }^{2}$ Department of Cardiothoracic Anaesthesia, National Heart Centre Singapore, Singapore

Address for Correspondence: Dr Zihui Tan, Department of Anaesthesiology, Singapore General Hospital, Outram Road, Singapore 169608.

Email: tan.zihui@singhealth.com.sg
} 
Care requirements of an ICU patient. Any area set aside for an ICU patient should ideally occupy a space adequate for a bed, ventilator and monitoring equipment (Table 1). There should be adequate room for movement around the patient during medical procedures, as well as space for a dialysis machine and an extracorporeal membrane oxygenator if required. Each cubicle should have its own dual oxygen, air, suction, water and electrical supply. Facilities housing COVID-19 patients should be isolated from the rest of the hospital to prevent cross-infection. Patients should ideally be isolated in single rooms, but if space is a constraint, cohorted patients in the same enclosed area should be placed at least 1 metre apart. ${ }^{11}$

Table 1. Requirements of level III ICU

\begin{tabular}{lll}
\hline Requirements & & \\
\hline Space & 1. & Physical space \\
& 2. & Oxygen source and supply \\
& 3. & Water supply \\
& 4. & Electrical supply \\
& 5. & Isolation facilities \\
& 6. & Negative pressure generation \\
\hline \multirow{2}{*}{ Staff } & 1. & Nursing \\
& 2. & Medical \\
& 3. & Allied Health \\
& 4. & Cleaning Staff \\
Supplies & 1. & Medications \\
& 2. & Equipment \\
\hline \multirow{2}{*}{ Standards } & 1. & Patient selection \\
& 2. & Education \\
& 3. & Psychosocial support \\
\hline
\end{tabular}

Although much attention has been focused on equipment such as ventilators and personal protective equipment (PPE), the main bottleneck for ICUs is skilled manpower. ${ }^{12}$ Each ICU bed will require 5 nurses to staff in order to provide a 1:1 nursing to patient ratio. Staffing for ICUs has traditionally been labourintensive and this baseline shortage is compounded by the prolonged training required to achieve competency. There is evidence that ICUs run by trained intensivists can reduce the mortality rate by over $40 \%$ but this is not feasible during a pandemic. ${ }^{13}$

In our centre, we have instituted "just-in-time" inter-professional and in situ simulations during the initial COVID-19 outbreak to upskill our nurses and physicians from other departments to increase the critical care work pool at short notice. These measures have helped to identify latent processes and system threats that led to downstream rectification. In addition, there has been a nationwide call for former healthcare professionals, or those currently in private practice, to register their interest in joining the Singapore Healthcare Corps, which would serve as additional manpower.

ORs are not designed for long-term patient care. Supplies required include physical equipment such as ICU beds, pressure relief mattresses, ventilators, syringe pumps, PPE and a wider range of medications beyond that found in anaesthetic carts. Although the ORs come with anaesthesia gas machines, there may be a need to nurse more than 1 patient in each OR, hence requiring additional transport ventilators. Critically ill patients are more likely to have complex issues requiring multiple medications, which would need a more sophisticated drug inventory and complex preparation. The drug inventories have to be managed appropriately by the pharmacists to ensure unexpired stocks and appropriate storage conditions. It is important to maintain critical care standards in the management of COVID-19 and its complications. This is challenging given that in the surge response, these patients are most likely cared for by staff who have not formally received critical care training. Education and timely dissemination of information is key but this can be hampered by social distancing measures. Any hands-on or face-to-face teaching session is limited to less than 10 medical staff at one time. Electronic platforms such as Zoom and WebEx have been used to conduct meetings. Learning material, guidelines and COVID-19-related resources are updated regularly on the intranet. Peer support hotlines have been set up to provide adequate peer and professional support for medical staff.

Oxygen supply. The volume of oxygen required in healthcare settings during peacetime can be staggering. ${ }^{14}$ In Singapore, liquid oxygen is stored in large quantities (up to 10,000 litres) in a vacuum insulated evaporator (VIE), which has a maximum oxygen flow rate of around 2,300 litres/min (L/min). During a pandemic where oxygen requirements are substantially increased, daily refilling of the VIE may be necessary as opposed to topping it up when it falls below a preset amount. It is mandatory that all hospital oxygen supply has a primary and secondary source. The amount of reserve source supply will depend on how much is consumed and how fast oxygen supply can be restored. At SGH, VIEs usually come with an oxygen backup from a cylinder manifold that provides up to 4 hours of emergency supply should the VIEs run dry. Hence, it 
is important to liaise with the facilities and machine engineering department early to determine the amount and source of oxygen supply.

In general, ICU ventilators require a much higher oxygen flow rate than anaesthesia gas machines, delivering flow rates of between $60-120 \mathrm{~L} / \mathrm{min} .{ }^{15}$ The minimum flow that has been shown to be adequate to drive current ventilators is $80 \mathrm{~L} / \mathrm{min}$ at $360 \mathrm{kPa} .{ }^{16} \mathrm{In}$ addition, ventilators on continuous positive airway pressure or non-invasive ventilation (NIV) modes can use an extraordinary amount of oxygen up to as high as 120L/ min. Hence, it is important to calculate the number of ventilators utilised and patients on NIV as their care can be affected. VIEs can run dry if total oxygen capacity is exceeded. Moreover, bellows-type ventilators are designed to function at 45-60 pounds per square inch. If pipeline pressures drop due to maximal oxygen flow rate being exceeded, it can result in disastrous outcomes for all ventilated patients in the hospital. Other alternatives include oxygen cylinders and oxygen concentrators.

Air flow and pressure systems in the ORs and PACU. The use of ORs can be attractive as they serve as isolation rooms equipped with an anaesthetic gas machine and monitoring devices. Surgery can also be potentially performed without the need for patient transfer. However, most ORs are positive-pressured, which is not desirable when AGPs such as intubation or suctioning are performed. To address this issue, OR doors must remain closed for at least 14-18 minutes after AGPs for the high efficiency particulate air filters to remove $99 \%$ of the particulate air matter since the OR air change rate is approximately 25 times per hour. ${ }^{17}$

PACU, on the other hand, is usually an open space with few, if any, isolation rooms. Hence, there is a risk of cross-infection between patients. As the PACU is located within the SGH operating theatre complex, it is also positive-pressured though lower than that in the ORs.

The possibility of creating temporary negative pressure ORs and PACU for isolating COVID-19 patients was explored in our centre. However, due to time and financial constraints, it was decided that non-COVID-19 ICU patients would be decanted to the ORs and PACU (Figs. 1 and 2), thus freeing up existing ICU facilities to nurse COVID-19 patients.

Purposing anaesthesia gas machines as ICU ventilators. Anaesthesia workstations are designed to support patients with different ventilatory requirements as well as to deliver inhalational anaesthetics throughout the course of surgery in a safe and efficient manner. However, prior to the COVID-19 pandemic, the use of anaesthesia gas machines for long-term ventilatory support was not approved by the US Food and Drug Administration (FDA) due to key differences from ICU ventilators, making them suboptimal for the care of critically ill patients. ${ }^{18}$

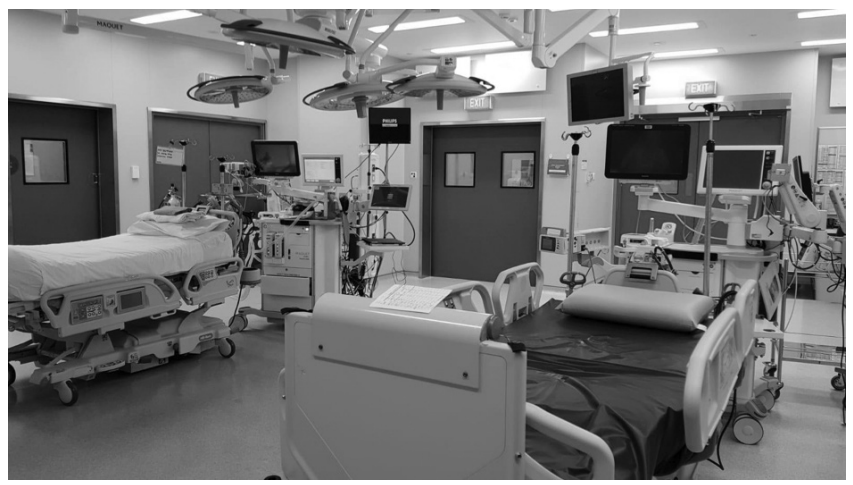

Fig.1. Operating room converted to temporary ICU.

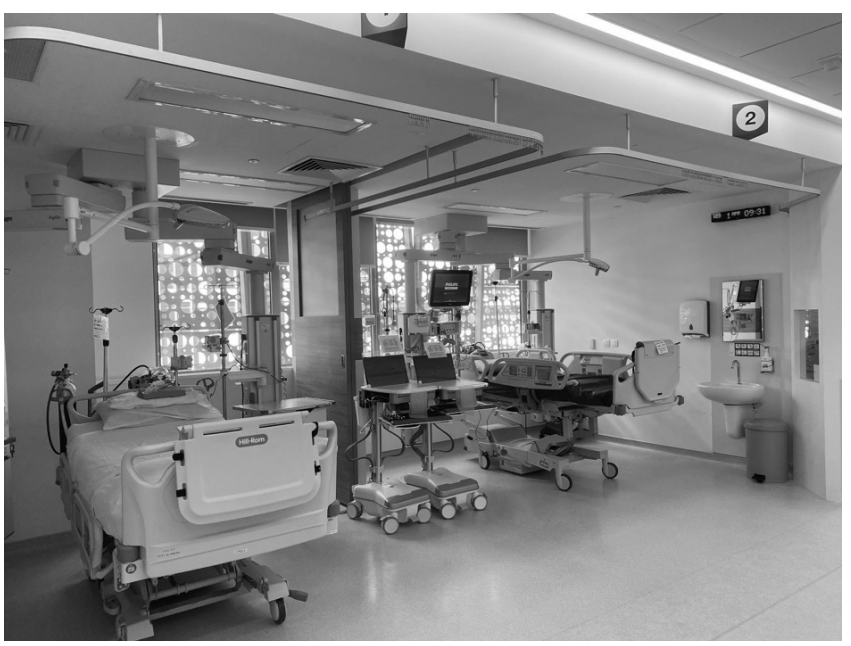

Fig. 2. Post-anaesthesia care unit converted to temporary ICU.

Due to the worldwide shortage of ICU ventilators to meet the potential needs of this worsening pandemic, the FDA granted temporary approval of the use of anaesthesia gas machines for patients requiring mechanical ventilation. ${ }^{19}$ Subsequently, various manufacturers and the Anaesthesia Patient Safety Foundation have issued notifications letters and statements detailing the off-label use of such devices for ICU ventilation..$^{18,20-23}$ As anaesthesia gas machines differ from ICU ventilators in terms of working principles and user interfaces, an anaesthesia professional familiar with 
the use of such devices should be immediately available at all times to manage and check on the machines at least every hour. ${ }^{18}$

In the current COVID-19 pandemic, physical space to care for patients as well as resources such as PPE are stretched. Non-traditional locations of ICU facilities may be required to cope with the surge. Although OR and PACU are not designed for long-term care of critically ill patients, they may be adapted to ICU use with careful planning in the current pandemic.

\section{Acknowledgment}

The authors would like to thank the Division of Anaesthesiology, Singapore General Hospital.

\section{REFERENCES}

1. Chen JI, Yap JC, Hsu LY, et al. COVID-19 and Singapore: From Early Response to Circuit Breaker. Ann Acad Med Singap 2020; 49:561-72

2. Chew SY, Lee YS, Ghimiray D, et al. Characteristics and Outcomes of COVID-19 Patients with Respiratory Failure Admitted to a "Pandemic Ready" Intensive Care Unit - Lessons from Singapore. Ann Acad Med Singap 2020;49:434-48.

3. Tan THY, Toh MPHS, Vasoo S, et al. Coronavirus Disease 2019 (COVID-19): The Singapore Experience. A Review of the First Eight Months. Ann Acad Med Singap 2020;49:764-78

4. Chen MIC, Leo YS, Ang BSP, et al. The outbreak of SARS at Tan Tock Seng Hospital - relating epidemiology to control. Ann Acad Med Singap 2006;35:317-25.

5. Goh K-T, Cutter J, Heng BH, et al. Epidemiology and control of SARS in Singapore. Ann Acad Med Singap 2006;35:301-16.

6. Tan CC. SARS in Singapore - key lessons from an epidemic. Ann Acad Med Singap 200635:345-9.

7. Guan WJ, Ni ZY, Hu Y, et al. Clinical Characteristics of Coronavirus Disease 2019 in China. N Engl J Med 2020;382:1708-20.

8. Young BE, Ong SWX, Kalimuddin S, et al. Epidemiologic Features and Clinical Course of Patients Infected With SARS-CoV-2 in Singapore. JAMA 2020;323:1488-94.

9. Grasselli G, Pesenti A, Cecconi M. Critical Care Utilization for the COVID-19 Outbreak in Lombardy, Italy: Early Experience and Forecast During an Emergency Response. JAMA 2020; 323:1545-6.

10. Hick JL, Einav S, Hanfling D, et al. Surge capacity principles: care of the critically ill and injured during pandemics and disasters: CHEST consensus statement. Chest 2014;146(4 Suppl): e1S-e16S.
11. World Health Organization. Infection Prevention and Control of Epidemic- and Pandemic-Prone Acute Respiratory Infections in Health Care, 2014.

12. Society of Critical Care Medicine. Shortage of ICU Providers Who Operate Ventilators Would Severely Limit Care During COVID-19 Outbreak, 14 March 2020. Available at: https://sccm.org/ getattachment/About-SCCM/Media-Relations/Final-Covid19-PressRelease.pdf?lang=en-US.

13. Leapfrog Ratings. ICU Physician Staffing, 2016. Available at: https://www.leapfroggroup.org/ratings-reports/icu-physician-staffing. Accessed on 8 April 2020.

14. Little CM, Merritt M, Wentworth A. An improvised oxygen supply system for pandemic and disaster use. Acad Emerg Med 2009; 16:558-63

15. Warner MA, Patel B. Mechanical ventilation. In: Benumof and Hagberg's Airway Management. Third edition. Amsterdam: Elsevier; 2013, pp. 981-97.

16. Department of Health. Health Technical Memorandum 02-01 : Medical Gas Pipeline Systems - Part A Design, Installation, Validation and Verification. Available at: http://www.bcga.co.uk/assets/ HTM_02-01_Part_A.pdf.

17. Ong S, Tan TK. Practical considerations in the anaesthetic management of patients during a COVID-19 epidemic. Anaesthesia 2020;75:823-4.

18. American Society of Anesthesiologist. APSF/ASA Guidance on Purposing Anesthesia Machines as ICU Ventilators, 7 May 2020. Available at: https://www.asahq.org/in-the-spotlight/coronaviruscovid-19-information/purposing-anesthesia-machines-for-ventilators. Accessed on 6 January 2021.

19. U.S. Food and Drug Administration. Center for Devices, Radiological Health. Ventilator Supply Mitigation Strategies, 22 March 2020. Available at: https://www.fda.gov/medical-devices/letters-health-careproviders/ventilator-supply-mitigation-strategies-letter-health-careproviders. Accessed on 5 April 2020.

20. GE Healthcare. GE's Health Effort to Address COVID-19. Available at: www.gehealthcare.com/corporate/covid-19. Accessed on 5 April 2020.

21. GE Healthcare. Topic: COVID-19 - Requests for information regarding the off-label use of GE Healthcare anesthesia devices for ICU ventilation, 23 March 2020. Available at: https://www. gehealthcare.com/-/jssmedia/3c655c83bd6b427e9824994c12be0da5. pdf?la=en-us. Accessed on 5 April 2020.

22. Dräger. COVID-19: Usage of Dräger anaesthesia devices for longterm ventilation, 18 March 2020. Available at: https://www.draeger. com/Library/Content/Draeger\%20Customer\%20Letter\%20-\%20 COVID-19\%20-\%20Usage $\% 20$ of $\% 20$ Anesthesia $\% 20$ devices $\% 20$ for $\% 201$ ong $\% 20$ term $\% 20$ ventilation-2020-03-18.pdf. Accessed on 5 April 2020.

23. Getinge. COVID-19 Pandemic Ventilating ICU patients using Flow-i, Flow-c and Flow-e anesthesia machines, 10 April 2020. Available at: https://www.getinge.com/dam/hospital/documents/ marketing-sales/customer-letters/english/mcv00103387_reva_ covid-19 customer letter_long_term_ventilation_with_flow-en-us. pdf. Accessed on 12 April 2020. 